\title{
THERMODYNAMIC ANALYSIS OF BASIC AND REGENERATIVE ORGANIC RANKINE CYCLES USING DRY FLUIDS FROM WASTE HEAT RECOVERY
}

\author{
E. Ozdemir ${ }^{1,}$, M. Kilic ${ }^{2}$
}

\begin{abstract}
The organic Rankine cycle (ORC), which generates electric energy using low temperature heat sources, is a promising technology in energy production sector. The ORC, which uses an organic fluid with its lower boiling point and higher vapor pressure than water-steam as a working fluid. The thermal efficiency of an ORC showes the performance of system, depends on system compenents, working fluid and operating conditions. This paper presents an thermodynamics examination of basic ORC and regenerative ORC for waste heat recovery applications using dry organic fluids. R113, R114, R227ea, R245fa and R600a with the boiling points from -16 ${ }^{\circ} \mathrm{C}$ to $48{ }^{\circ} \mathrm{C}$ are selected in the analyses. The relationships between the ORC's performance parameters for basic and regenerative technologies and the properties of working fluids are evaluated based on various turbine inlet pressure values. Results show that regenerative ORC has higher thermal efficiency compared with basic ORC. Also, the thermal efficiency increases with the increment of the turbine inlet pressure for both basic ORC and regenerative ORC.
\end{abstract}

Keywords: Energy, Exergy, Working Fluid, Organic Rankine Cycle, Regenerative Organic Rankine Cycle

\section{INTRODUCTION}

Energy is one of the most important sources to sustain life. Energy management and diversifying of energy resources are considered a significant way to increase energy efficiency, reduce greenhouse gas emissions and energy costs. Globally, fossil fuels continue to meet a dominant share of global energy demand, with implications for the links between energy, the environment and climate change. About $65 \%$ of the world energy consumption is supplied from fossil fuels which are increasingly disappearing and damage the ecology in the world. Consequently, the countries of the world target that renewable energy resources are used in energy conversion technology.

Organic Rankine cycle (ORC) which generates electricity from renewable energy resources and waste heat, is an environmentally-friendly technology. The working principal of an ORC is similar to the common vapor Rankine cycle. However, it uses an organic fluid which has high molecular mass hydrocarbon compound, low critical temperature and pressure instead of water-steam as a working fluid. Useable heat resources in ORC are solar energy, geothermal energy, biomass products, surface seawater and waste heat from various thermal processes.

Many studies on ORC have been presented in the literature. For example, Liu et al. [1] used total heatrecovery efficiency and heat availability instead of thermal efficiency as the evaluation criteria to optimize the working fluid and operating conditions for organic rankine cycle. Chen et al. [2] compared the system performance between a supercritical Rankine cycle using $\mathrm{CO}_{2}$ as working fluid and a subcritical ORC using R123 as working fluid. Kanoglu and Bolatturk [3] assessed the thermodynamic performance of the Reno (Nevada, USA) binary plant. This plant uses geothermal fluid at $158{ }^{\circ} \mathrm{C}$ and isobutene as working fluid. Exergy and energy efficiency obtained were $21 \%$ and $10.20 \%$, respectively. Roy et al. [4] analyzed non-regenerative $\mathrm{ORC}$, based on the parametric optimization, using R-12, R-123, R-134a and R-717 as working fluids superheated at constant pressure. Gao et al. [5] analyzed the performance of supercritical ORC driven by exhaust heat using 18 organic working fluids. They recommended that both the higher output and the lower investment, the following working fluids for the supercritical ORC system were R152a and R143a. Dai et al.[6] investigated ORCs for low-grade waste heat recovery with different working fluids. Thermodynamic properties for each working fluid were investigated and the cycles were optimized with exergy efficiency as an objective function using genetic algorithms. The authors showed that the cycles with organic working fluids were better than the 
cycle with water for converting low-grade waste heat to useful work. The cycle with R236EA exhibited the highest exergy efficiency. Adding an internal heat exchanger to the ORC did not improve the performance under the given waste heat conditions. Kerme and Orfi [7] modeled ORC driven by parabolic through solar collectors to investigate the effect of turbine inlet temperature on main energetic and exergetic performance parameters for eight working fluids and o-xylene showed the maximum energetic and exergetic performance. Wang et al. [8] analyzed a double ORC for discontinuous waste heat recovery. Wang et al. [9] optimized the working fluid and parameters of ORC system with simulated annealing algorithm. They compared the results of 13 working fluids. Kaska[10] analyzed a waste heat driven organic Rankine cycle and assessed performance of the cycle and pinchpoint sites of primary exergy destruction using actual plant data. Zhu et al. [11] assessed the performances of ORC under saturated expansion using organic and isentropic fluids, and under superheated expansions using organic wet fluids. Koroglu and Sogut [12] examined a marine power plant with ORC using energy and exergy analyses. Their results demonstrated that the best fluid for ORC system was R113 with respect to the highest net power output, lowest exergy destruction, energy and exergy efficiencies.Yu et al. [13] evaluated working fluid selection considering the characteristics of the waste heat source for ORC system. Radulovic [12] investigated suitability of several wet, dry and isentropic fluids in a supercritical Rankine cycle. His results shows that R134a refrigerant illustrates superior exergetic efficiency at high evaporator pressures. Akkaya [15] developed a thermodynamic model to investigate the effect of ambient conditions on performance of an ORC.

Some researchers also have worked on regenerative ORC. Mago et al. [16] evaluated an analysis of regenerative organic Rankine cycles using dry organic fluids, to convert waste energy to power from low- grade heat sources. They selected four dry organic working fluids which are R113, R245ca, R123 and isobutene and analyzed basic ORC and regenerative ORC using a combined first and second law analysis at various reference temperatures and pressures. Hajabdollahi et al. [17] optimized the regenerative solar ORC. They selected evaporator pressure, condenser pressure, refrigerant mass flow rate, number of solar panel, storage capacity and regenerator effectiveness as design parameters and compared with R245fa and R123. Wang et al. [18] modeled a regenerative ORC for utilizing solar energy over a range of low temperatures, considering flat-plate solar collectors and thermal storage systems. They showed that system performance could be improved, under realistic constraints, by increasing turbine inlet pressure and temperature or lowering the turbine backpressure, and by using a higher turbine inlet temperature with a saturated vapor input. Darvish et al. [19] simulated the thermodynamic performance of regenerative ORC to select proper organic working fluids using nine working fluids. Roy et al. [20] analyzed regenerative ORC, based on optimization using R-123 and R-134a during superheating at a constant pressure of 2,50 MPa. Imran et al. [21] evaluated the thermo-economic optimization of basic ORC and regenerative ORC for waste heat recovery applications under constant heat source condition.

The brief review above shows that the types of working fluids have a significant influence on the performance of ORC. ORC could be used to recover low grade waste heat. In this paper, with the light of studies in literature, the energy and exergy analysis of basic and regenerative organic Rankine cycle is performed for different dry working fluids which are R113, R114, R227ea, R245fa and R600a. The organic Rankine cycle's performance parameters are evaluated depending on varied turbine inlet pressures of the working fluid. The exergy efficiency, thermal efficiency, the irreversibility rate, the net power, the outlet temperature of waste hot fluid or the evaporation temperature are calculated with the various turbine inlet pressures. Results from the analyses show that turbine inlet pressure and the selection of working fluid have significant effect on the performance parameters of an ORC. Also the R113 working fluid produces higher thermal efficiency, exergy efficiency, net power and lower total irreversibility rate under accepted conditions in compared with other working fluid in basic and regenerative ORC.

\section{MATERIAL AND METHOD}

\section{Organic Rankine Cycle}

The schematic diagram of a basic ORC system is shown in Figure 1. It includes four components: evaporator (boiler), expander, condenser and pump. An ORC consists of four phases: Pressure increase in the condensate in the feed pump from pressure $\mathrm{p}_{1}$ to $\mathrm{p}_{2}$. Isobaric heating, evaporation and overheating of the working fluid in the evaporator (boiler) at constant pressure $\mathrm{p}_{2}=\mathrm{p}_{3}$. Expansion of the vapor working medium in an expansion machine (e.g. a turbine) from pressure $\mathrm{p}_{3}$ to $\mathrm{p}_{4}$. Isobaric heat release, complete condensation and possible under-cooling of the working medium in the condenser at constant pressure $\mathrm{p}_{4}=\mathrm{p}_{1}$. 


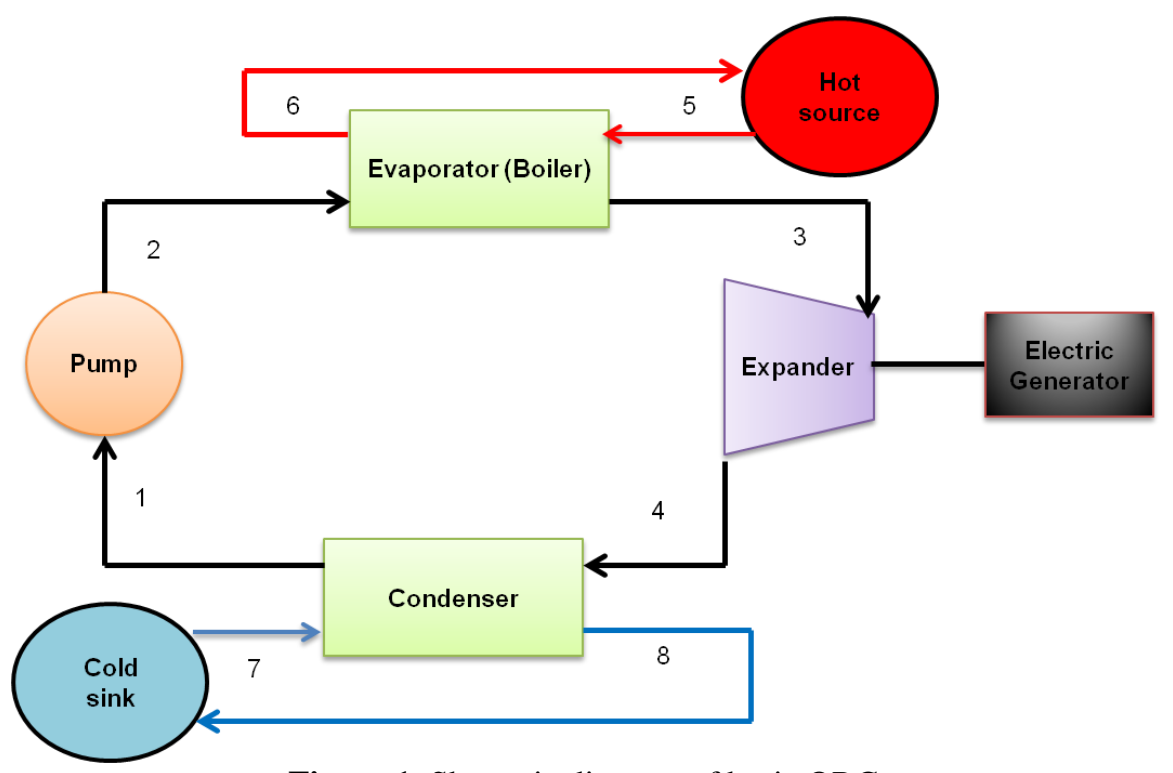

Figure 1. Shematic diagram of basic ORC

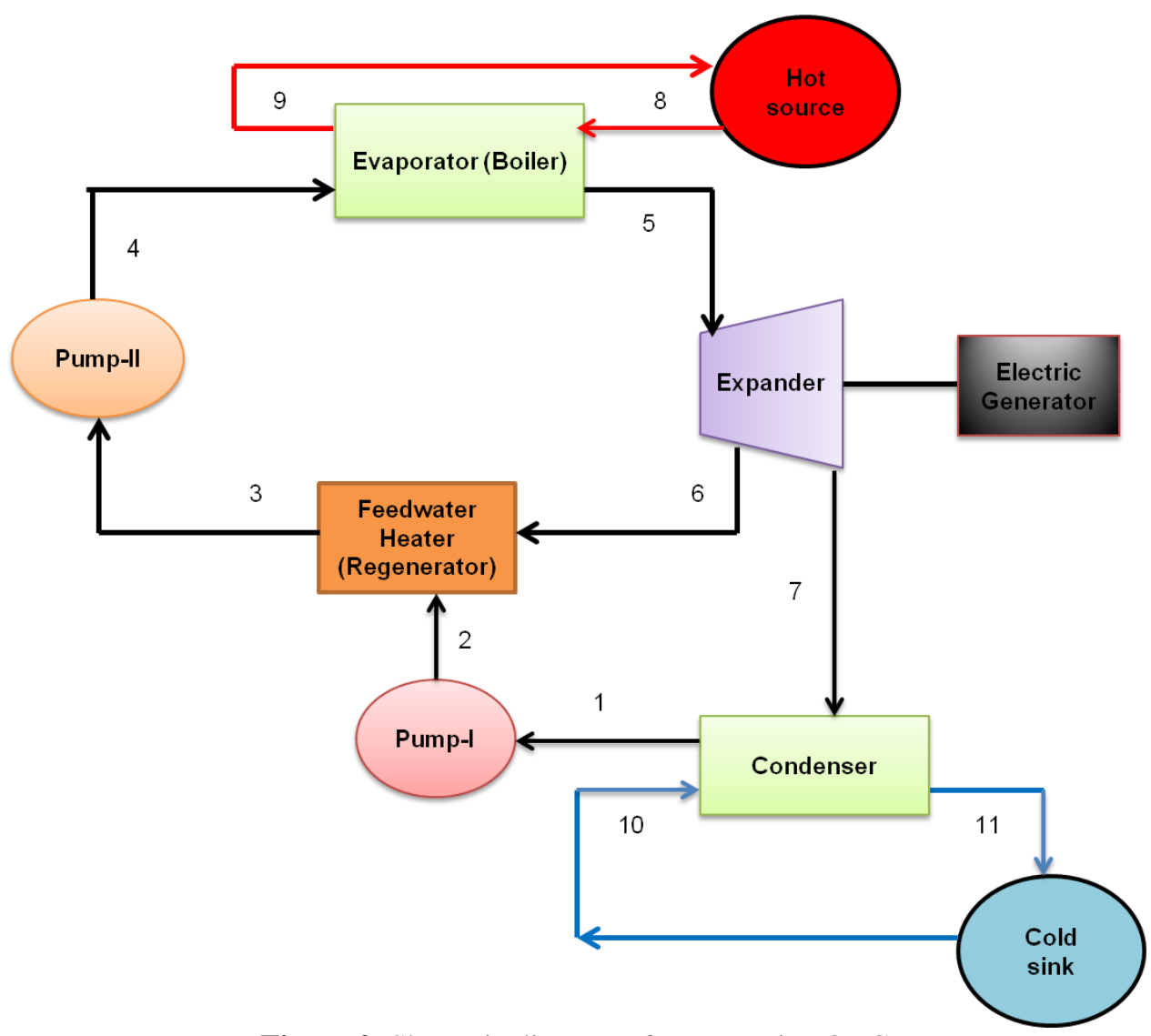

Figure 2. Shematic diagram of regenerative ORC

Figure 2 presents a schematic diagram of the regenerative ORC used to obtain energy from waste thermal energy. It is comprised of an evaporator (boiler), expander, feedwater heater (regenerator), condenser and two pumps. In the regenerator heat exchanger, heat is transferred between the high temperature vapor at the expander outlet and the low temperature fluid at the pump outlet in order to avoid energy loss [19]. In an regenerative ORC, steam enters the expander at the evaporator pressure (state 5) and expands isentropically to an intermediate pressure (state 6). Some steam is extracted at this state and routed to the feedwater heater, while the remaining steam continues to expand isentropically to the condenser pressure (state 7). This steam leaves the 
condenser as a saturated liquid at the condenser pressure (state 1). The condensed water, which is also called the feedwater, then enters an pump-I, in which the pressure is raised to the feedwater heater pressure (state 2) and is routed to the feedwater heater, where it mixes with the steam extracted from the expander. The mixture leaves the heater as a saturated liquid at the heater pressure (state 3). The pump-II raises the pressure of the working fluid to the evaporator pressure (state 4). The cycle is completed by evaporating the working fluid in the boiler (state 5) [18].

Working fluids for ORC's are categorized in three groups based on their slope of saturation vapor curves in $\mathrm{T}-\mathrm{s}$ diagram. The fluids having positive slope are dry fluids (ds/dT $>0$ ). The fluids having negative slope are wet fluids $(\mathrm{ds} / \mathrm{dT}<0)$. The fluids having nearly infinitely large slopes are isentropic fluids $(\mathrm{ds} / \mathrm{dT}=0)$. In the ORC, dry or isentropic fluids are more favourable because they do not require superheating in the evaporator in order to avoid forming moisture in the working fluid during the expansion process.

In this study, R600a, R245fa, R227ea, R113 and R114 dry fluids are selected as the working fluids. Table 1 shows the thermo-physical properties of the selected fluids. It can be seen from Table 1 that R113 has the highest value of boiling point temperature. It is followed by R245fa, R114, R600a and R227ea respectively.

Table 1. Thermo-physical properties of the selected fluids [19]

\begin{tabular}{|l|r|r|r|r|r|}
\hline \multicolumn{1}{|c|}{ Parameters } & R600a & R245fa & R227ea & R113 & \multicolumn{1}{c|}{ R114 } \\
\hline Molecular mass (g/mol) & 58.12 & 134.05 & 170.03 & 187.38 & 170.92 \\
\hline Formula & $\mathrm{C}_{4} \mathrm{H}_{10}$ & $\mathrm{C}_{3} \mathrm{~F}_{5} \mathrm{H}_{3}$ & $\mathrm{C}_{3} \mathrm{~F}_{7} \mathrm{H}$ & $\mathrm{C}_{2} \mathrm{Cl}_{3} \mathrm{~F}_{3}$ & $\mathrm{C}_{2} \mathrm{Cl}_{2} \mathrm{~F}_{4}$ \\
\hline Maximum temperature (K) & 575.00 & 440.00 & 475.00 & 525.00 & 507.00 \\
\hline Maximum pressure (MPa) & 35.00 & 200.00 & 60.00 & 200.00 & 21.00 \\
\hline Critical point temperature (K) & 407.70 & 427.01 & 374.90 & 487.10 & 418.83 \\
\hline Critical point pressure (MPa) & 3.63 & 3.65 & 2.92 & 3.39 & 3.26 \\
\hline Critical point density (kg/m $\left.{ }^{\mathbf{3}}\right)$ & 225.50 & 519.43 & 594,25 & 560,00 & 579.97 \\
\hline Boiling temperature $\left({ }^{\mathbf{0}} \mathbf{C}\right)$ & -11.68 & 15.18 & -16.25 & 47.59 & 3.79 \\
\hline
\end{tabular}

\section{System Description and Modeling}

The analysis of an ORC based on thermodynamic laws and the energy, exergy analyses were performed for the working fluids investigated. For simplicity, the following assumption were made:

$\checkmark \quad$ All processes are operating at steady state.

$\checkmark$ The thermal and friction losses in the pipes are negligible.

$\checkmark \quad$ The kinetic and potential energy changes are negligible.

$\checkmark$ The working fluid is in saturated liquid at condenser exit and feedwater heater exit for regenerative ORC.

$\checkmark$ Pressure drops of working fluid in the evaporator and condenser is neglected.

$\checkmark \quad$ The heat loss from the ORC components is negligible.

$\checkmark \quad$ There are only two pressures: an evaporating pressure $\mathrm{p}_{\mathrm{e}}$ and a condensing pressure $\mathrm{p}_{\mathrm{c}}$ for basic ORC.

$\checkmark \quad$ The isentropic efficiency of expander (turbine) $\eta_{t}$ and the pumps $\eta_{p}$ are 0.80 .

$\checkmark$ Atmospheric condition is taken as $100 \mathrm{kPa}$ and $293.15 \mathrm{~K}$.

$\checkmark$ The mass flow rate $m_{h f}$ and the specific heat capacity $c_{p}$ of the hot fluid are $1 \mathrm{~kg} / \mathrm{s}$ and $1 \mathrm{~kJ} / \mathrm{kgK}$ respectively.

$\checkmark \quad$ The minimum temperature difference $\Delta T_{p p}$ in the evaporator is $5 \mathrm{~K}$.

$\checkmark \quad$ The cooling medium temperature $T_{L}$ is $293.15 \mathrm{~K}$.

$\checkmark$ Turbine inlet temperature is taken $15^{\circ} \mathrm{C}$ lower than the temperature of the hot fluid [16].

$\checkmark$ The inlet temperature of hot fluid in evaporator is $250^{\circ} \mathrm{C}$.

$\checkmark$ The turbine inlet pressure is taken as from $1000 \mathrm{kPa}$ to the critical pressure of each working fluid.

For any steady state control volume, by neglecting the potential and kinetic energy changes, general expression of mass, energy and exergy balance equations are that $[16,17,21,22]$ : 
Energy balance equation:

$$
\sum m_{\text {ln }}=\sum m_{\text {out }}
$$

Energy balance equation:

$$
\begin{aligned}
\dot{E_{\text {ln }}} & =E_{\text {out }}^{\cdot} \\
\dot{Q}+\dot{W} & =\sum m_{\text {out }} h_{\text {out }}-\sum \dot{m_{\text {ln }}} h_{\text {in }}
\end{aligned}
$$

Exergy balance equation:

$$
\sum E \dot{x}_{\text {ln }}-\sum E \dot{x}_{\text {out }}-E \dot{x}_{d}=\Delta E \dot{x}_{s}
$$

where for a steady-state system, $\Delta E \dot{x_{S}}$ is zero.

$$
\begin{gathered}
E \dot{x}_{\text {ln }}=E \dot{x}_{\text {out }} \\
E \dot{x_{\text {heat }}}+\dot{W}=E \dot{x_{\text {out }}}-E \dot{x}_{\text {ln }}+\dot{I}
\end{gathered}
$$

where, subscripts in and out represent the inlet and exit states, $\dot{Q}$ is heat input, $\dot{W}$ is work input, $\dot{E x}$ is exergy rate and $\dot{I}$ is the irreversibility rate.

\section{Basic Organic Rankine Cycle}

\section{Process 1-2 (pump)}

The isentropic efficiency of the pump:

$$
\eta_{p}=\left(h_{2 s}-h_{1}\right) /\left(h_{2}-h_{1}\right)
$$

The pump power:

$$
\dot{W}_{p}=\frac{m_{w f}\left(h_{2 s}-h_{1}\right)}{\eta_{p}}=m_{w f}\left(h_{2}-h_{1}\right)
$$

The irreversibility of the pump:

$$
\dot{I}_{p}=\left(\dot{E}_{1}-\dot{E}_{2}\right)+\dot{W}_{p}=\mathrm{T}_{0} \Delta S_{p}
$$

\section{Process 2-3 (evaporator)}

During the above heat exchange, the temperature of hot fluid decreases from $T_{5}$ to $T_{6}$. The specific heat capacity $\mathrm{C}_{p}$ of the hot fluid at constant pressure is assumed to be constant.

The evaporator heat rate:

$$
\begin{gathered}
\dot{Q_{e}}=m_{w f}\left(h_{3}-h_{2}\right)=m_{h f}\left(h_{5}-h_{6}\right) \\
\dot{Q_{e}}=m_{h f} C p\left(T_{5}-T_{6}\right)
\end{gathered}
$$

The irreversibility of the evaporator:

$$
\dot{I_{e}}=\left(\dot{E_{2}}-\dot{E_{3}}\right)+\left(\dot{E_{5}}-\dot{E_{6}}\right)
$$


Journal of Thermal Engineering, Research Article, Vol. 4, No. 5, pp. 2381-2393, July, 2018

$$
\dot{I}_{e}=T_{0} m_{w f}\left[\left(s_{3}-s_{2}\right)-\frac{2\left(h_{3}-h_{2}\right)}{\left(T_{5}+T_{6}\right)}\right]
$$

\section{Process 3-4 (expander)}

The isentropic efficiency of the expander:

$$
\eta_{\text {exp }}=\left(h_{3}-h_{4}\right) /\left(h_{3}-h_{4 s}\right)
$$

The expander power:

$$
W_{\text {exp }}=m_{w f}\left(h_{3}-h_{4 s}\right) \eta_{\text {exp }}=m_{w f}\left(h_{3}-h_{4}\right)
$$

The irreversibility of the expander:

$$
I_{\text {exp }}^{\cdot}=\left(\dot{E_{3}}-\dot{E_{4}}\right)-\dot{W_{e x p}}=\mathrm{T}_{0} \Delta S_{\text {exp }}
$$

\section{Process 4-1 (condenser)}

The condenser heat rate:

$$
\dot{Q_{c}}=m_{w f}\left(h_{4}-h_{1}\right)
$$

The irreversibility of the condenser:

$$
\begin{aligned}
& \dot{I}_{c}=\left(\dot{E_{4}}-\dot{E_{1}}\right)+\left(\dot{E_{7}}-\dot{E_{8}}\right)=\mathrm{T}_{0} \Delta S_{c} \\
& \dot{I}_{c}=T_{0} \dot{m}_{w f}\left[\left(s_{1}-s_{4}\right)-\frac{\left(h_{1}-h_{4}\right)}{T_{L}}\right]
\end{aligned}
$$

The thermal efficiency $\left(\eta_{t h}\right)$ of the ORC system is the ratio of the net power output to the heat input. It can be expressed as:

$$
\eta_{t h}=\frac{W_{n e t}^{\cdot}}{\dot{Q}_{e}}=\frac{W_{e x p}-\dot{W}_{p}}{\dot{Q}_{e}}
$$

The exergy destruction rate of ORC system $\left(\dot{E}_{d}=\dot{I}\right)$ can be expressed as:

$$
\begin{gathered}
\dot{E_{d}}=I_{\text {cycle }}=I_{\text {exp }}+\dot{I}_{c}+\dot{I_{p}}+\dot{I}_{e} \\
I_{c y c l e}=T_{0} m_{w f}\left[-\frac{2\left(h_{3}-h_{2}\right)}{\left(T_{5}+T_{6}\right)}-\frac{\left(h_{1}-h_{4}\right)}{T_{L}}\right]
\end{gathered}
$$

The exergy efficiency of ORC:

$$
\eta_{\text {exe }}=\frac{W_{\text {net }}^{\cdot}}{W_{n e t}^{\cdot}+\dot{E_{d}}}=\frac{W_{\text {net }}^{\cdot}}{\dot{Q}_{e}\left(1-\frac{2 T_{L}}{\left(T_{5}+T_{6}\right)}\right)}
$$

\section{Regenerative Organic Rankine Cycle}

\section{Feed-water Heater}


The passed through the turbine working fluid separates two parts. The $\mathrm{X}$ amount of the working fluid enters the feed-water heater and the (1-X) amount of the working fluid enters the condenser. These processes are showed with the number 6 and 7 in the Figure 2. When practiced the energy balance equation in this section;

$$
\mathrm{X}=\frac{\mathrm{h}_{3}-\mathrm{h}_{2}}{\mathrm{~h}_{6}-\mathrm{h}_{2}}
$$

\section{Process 1-2 and 3-4 (pump-I and pump-II)}

The power of pumps:

$$
\begin{aligned}
& \dot{W}_{p 1}=\frac{m_{w f}(1-X)\left(h_{2 s}-h_{1}\right)}{\eta_{p}} \\
& \dot{W}_{p 2}=\frac{m_{w f}\left(h_{4 s}-h_{3}\right)}{\eta_{p}}
\end{aligned}
$$

The irreversibility of the pumps:

$$
\dot{I_{p}}=\dot{T_{0}} m_{w f}\left[(1-X)\left(s_{1}-s_{2}\right)+\left(s_{3}-s_{4}\right)\right]
$$

\section{Process 4-5 (evaporator)}

The evaporator heat rate:

$$
\dot{Q_{e}}=m_{w f}\left(h_{5}-h_{4}\right)
$$

The irreversibility of the evaporator:

$$
\dot{I}_{e}=T_{0} \quad m_{w f}\left[\left(s_{5}-s_{4}\right)-\frac{2\left(h_{5}-h_{4}\right)}{\left(T_{8}+T_{9}\right)}\right]
$$

\section{Process 5-6 and 5-7 (expander)}

The expander power:

$$
W_{\text {exp }}=m_{w f} \eta_{\exp }\left[\left(h_{5}-h_{7 s}\right)+X\left(h_{7 s}-h_{6 s}\right)\right.
$$

The irreversibility of expander:

$$
I_{e x p} \cdot \mathrm{T}_{0} m_{w f}^{\cdot}\left[\left(s_{7}-s_{5}\right)+X\left(s_{6}-s_{7}\right)\right]
$$

\section{Process 7-1 (condenser)}

The condenser heat rate:

$$
\dot{Q}_{c}=m_{w f}^{\cdot}(1-X)\left(h_{1}-h_{7}\right)
$$

The irreversibility of condenser:

$$
\dot{I}_{c}=T_{0} \quad m_{w f}(1-X)\left[\left(s_{1}-s_{7}\right)-\frac{\left(h_{1}-h_{7}\right)}{T_{L}}\right]
$$


The thermal efficiency $\left(\eta_{t h}\right)$ of the regenerative ORC is:

$$
\eta_{t h}=\frac{W_{n e t}}{\dot{Q}_{e}}=\frac{\dot{W}_{t}-\dot{W}_{p}}{\dot{Q}_{e}}
$$

The exergy efficiency of regenerative ORC:

$$
\eta_{\text {exe }}=\frac{W_{n e t}^{\cdot}}{W_{n e t}^{\cdot}+E_{d}}=\frac{W_{n e t}^{\cdot}}{\dot{Q}_{e}\left(1-\frac{2 T_{L}}{\left(T_{8}+T_{9}\right)}\right)}
$$

The total irreversibility can be expressed as:

$$
I_{\text {cycle }}=T_{0} m_{w f}\left[-\frac{2\left(h_{5}-h_{4}\right)}{\left(T_{8}+T_{9}\right)}-(1-X) \frac{\left(h_{1}-h_{7}\right)}{T_{L}}\right]
$$

\section{RESULTS AND DISCUSSION}

For the aim of this study five organic fluids were selected in the analysis as a working fluid which were R113, R114, R227ea, R245fa and R600a with boiling temperatures ranging from $-16{ }^{\circ} \mathrm{C}$ to $48{ }^{\circ} \mathrm{C}$. The turbine inlet temperature was defined as $15{ }^{\circ} \mathrm{C}$ lower than the temperature of the hot fluid. The inlet temperature of hot fluid in evaporator is $250{ }^{\circ} \mathrm{C}$. In addition, turbine inlet pressure was taken as from $1000 \mathrm{kPa}$ to the critical pressure of each working fluid. Figure 3 showes the comparison of the thermal efficiency for organic working fluids. The working fluids with greater thermal efficiency to lower one are R113, R245fa, R114, R600a and R227ea. The thermal and exergy efficiency increases with the increment of the turbine inlet pressure for both basic ORC and regenerative ORC as shown in Figure 3, Figure 4 and Figure 5.

When the thermal efficiency is evaluated with the net power and the heat input in the evaporator, the net power and heat input decreases but the thermal efficiency still increases which shows that the decrease of the heat absorbed by the working fluid (Qev) is greater than on the decrease of the net power (Wnet).

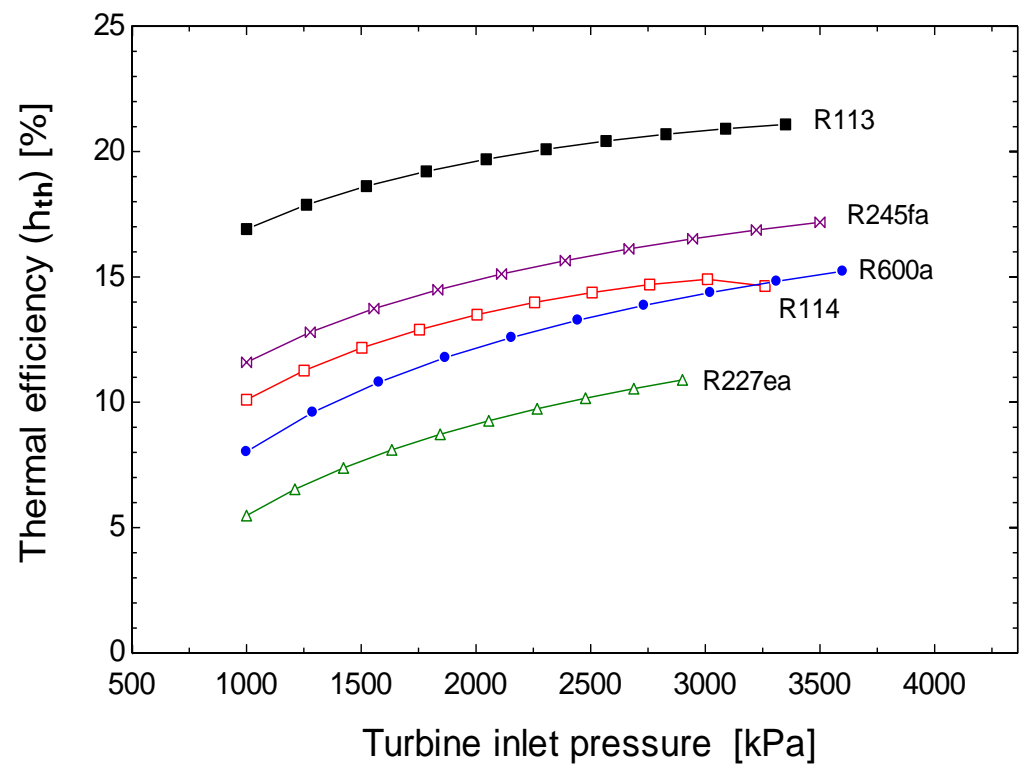

Figure 3. Variation of the system thermal efficiency with the turbine inlet pressure for basic ORC

When compared the exergy efficiency of the working fluid, R113 fluid which is followed by R245fa, R600a, R114 and R227ea, has the highest second law efficiency. Also, the results represent same collacation with boiling temperature. The best thermal and exergy efficiency is R113, which has the highest boiling among the selected fluids, while R227ea working fluid has the worst thermal and exergy efficiency and which has the lowest boiling point temperature. 


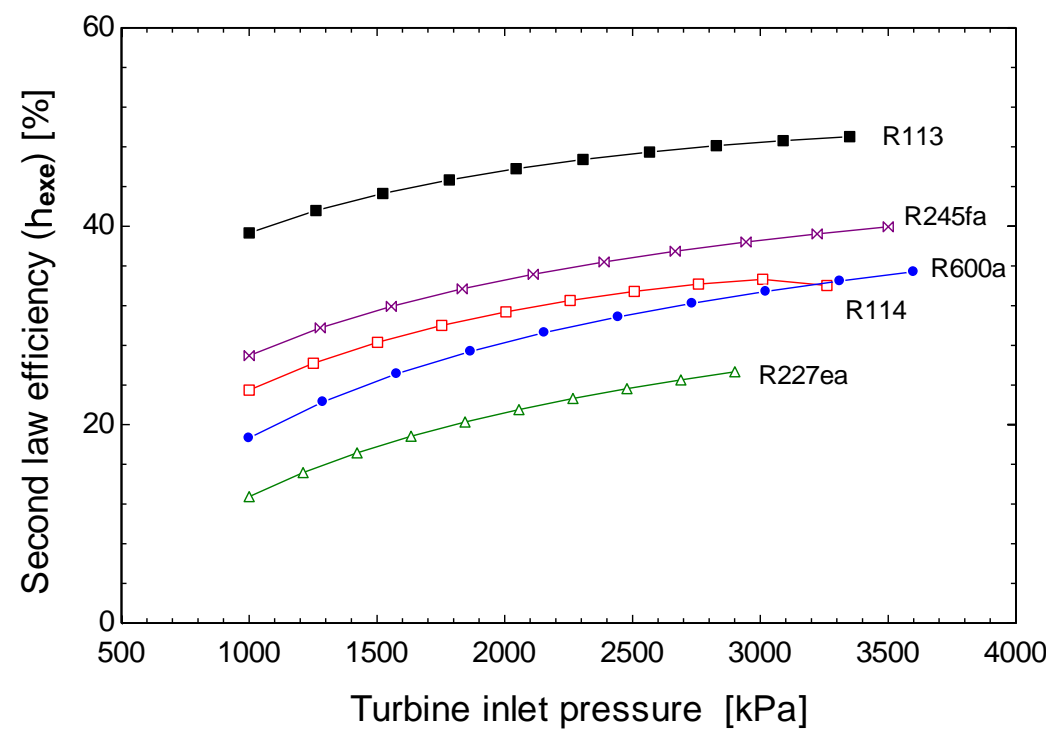

Figure 4. Variation of the system exergy (second law) efficiency with the turbine inlet pressure for basic ORC

As is seen the Table 2, R113 working fluid has minimum the mass of working fluid, the heat input in the evaporator and the total irreversibility rate when the turbine inlet pressure is $1 \mathrm{MPa}$ and the temperature of waste hot source is $250{ }^{\circ} \mathrm{C}$. The maximum net power with $51.68 \mathrm{~kW}$ value is calculated for $245 \mathrm{fa}$. $\mathrm{R} 113$ working fluid products $50.98 \mathrm{~kW}$ net power. However, when examined heat input in the evaporator, this value is higher than R113's. For this reason, the thermal and exergy efficiency of R113 are obtained as $17 \%$ and $39 \%$ respectively. The lowest the net power, thermal and exergy efficiency values are gotten for R227ea working fluid with 35.32 $\mathrm{kW}, 5 \%$ and $13 \%$ respectively. The working fluids with greater irreversibility rate to lower one are R227ea, R600a, R114, R245fa and R113.

Table 2. The comparison of the selected fluids $\left(\mathrm{P}_{3}=1 \mathrm{MPa}\right.$ and $\left.\mathrm{T}_{5}=250{ }^{\circ} \mathrm{C}\right)$

\begin{tabular}{|l|c|c|c|c|c|c|c|}
\hline Fluid & $\begin{array}{c}\boldsymbol{m}_{\boldsymbol{w f}} \\
(\boldsymbol{k g} / \boldsymbol{s})\end{array}$ & $\begin{array}{c}\boldsymbol{T}_{\boldsymbol{e}} \\
\left({ }^{\circ} \mathrm{C}\right)\end{array}$ & $\begin{array}{c}\boldsymbol{W}_{\text {net }} \\
(\boldsymbol{k} \boldsymbol{W})\end{array}$ & $\begin{array}{c}\boldsymbol{Q}_{\boldsymbol{e v}} \\
(\boldsymbol{k} \boldsymbol{W})\end{array}$ & $\begin{array}{c}\boldsymbol{\eta}_{\text {th }} \\
(\%)\end{array}$ & $\begin{array}{c}\boldsymbol{\eta}_{\text {exe }} \\
(\%)\end{array}$ & $\begin{array}{c}\boldsymbol{I}_{\text {cycle }} \\
(\boldsymbol{k W})\end{array}$ \\
\hline R113 & 0.99 & 139.20 & 50.98 & 301.40 & 17.00 & 39.00 & 77.34 \\
\hline R114 & 1.62 & 83.58 & 49.07 & 485.80 & 10.00 & 23.00 & 157.2 \\
\hline R227ea & 2.03 & 53.50 & 35.32 & 644.60 & 5.00 & 13.00 & 237.9 \\
\hline R245fa & 1.08 & 89.61 & 51.68 & 445.90 & 12.00 & 27.00 & 137.8 \\
\hline R600a & 1.65 & 66.23 & 41.37 & 515.30 & 8.00 & 18.00 & 177,2 \\
\hline
\end{tabular}

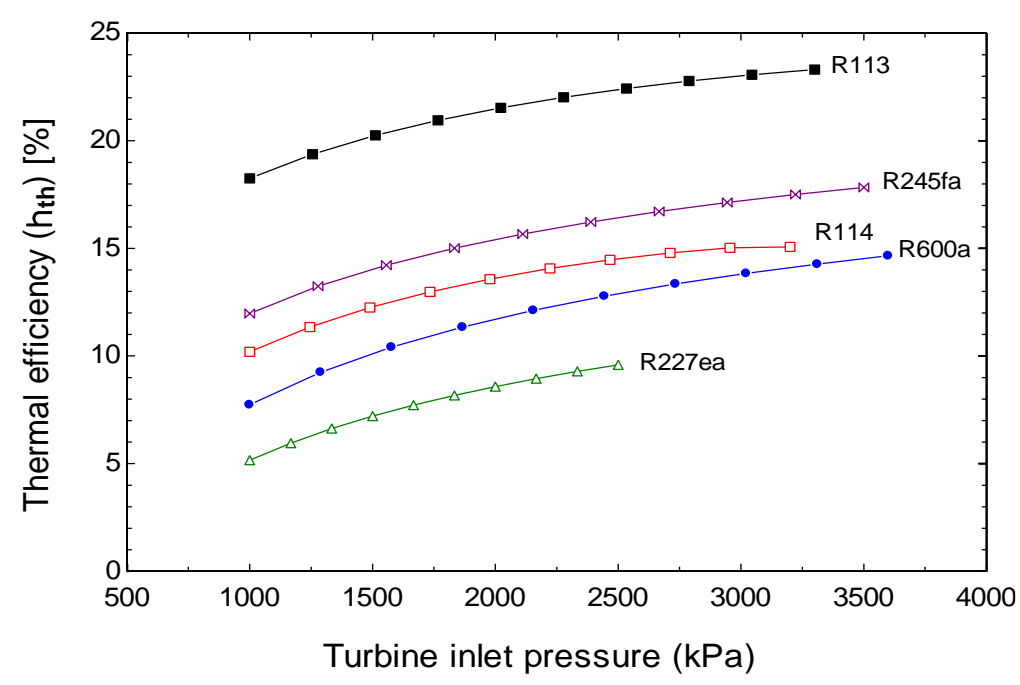

Figure 5. Variation of the system thermal efficiency with the turbine inlet pressure for regenerative ORC 
Figure 5 illustrates the variation of the system first law efficiency with turbine inlet pressure for selected working fluids in the analysis of regenerative ORC. It can be seen that in both basic and regenerative ORC, the same trend for the thermal efficiency is observed and R113 working fluid represents the best performance. The worst efficiency is calculated for R227ea which is followed by R600a, R114 and R245fa.

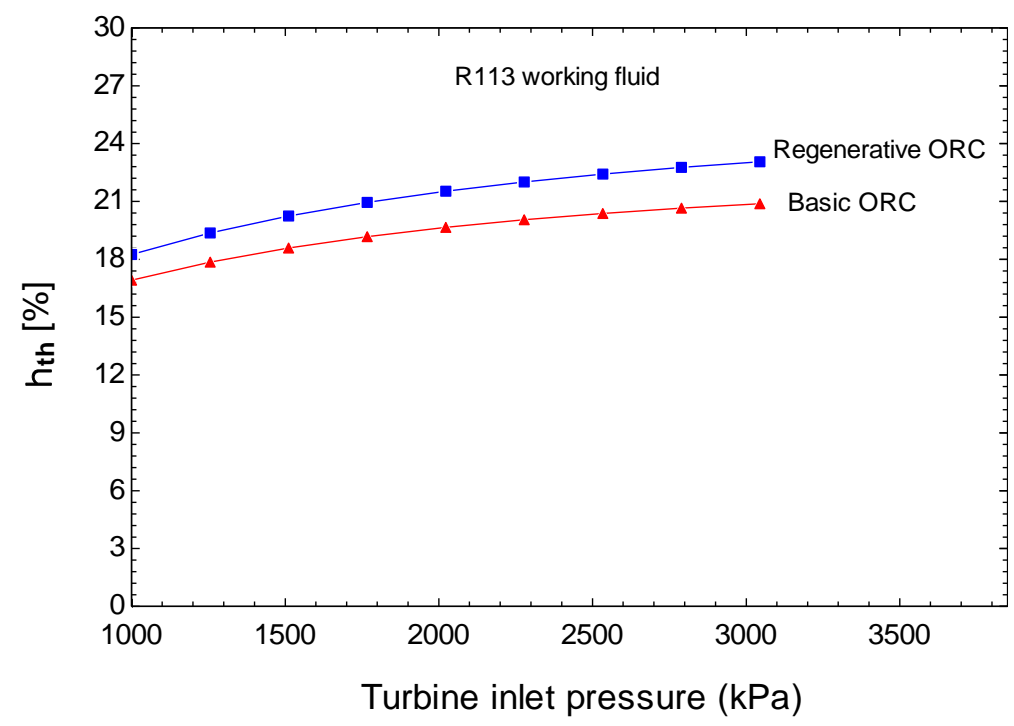

Figure 6. Comparison of thermal efficiency for basic and regenerative ORC

A comparison between the two cycles shows that the thermal efficiency of regenerative ORC is about $8 \%$ higher than the thermal efficiency of basic ORC in low-inlet pressures while with using regenerative ORC in high- pressures, the thermal efficiency increases by 15,4\% compared with basic ORC.

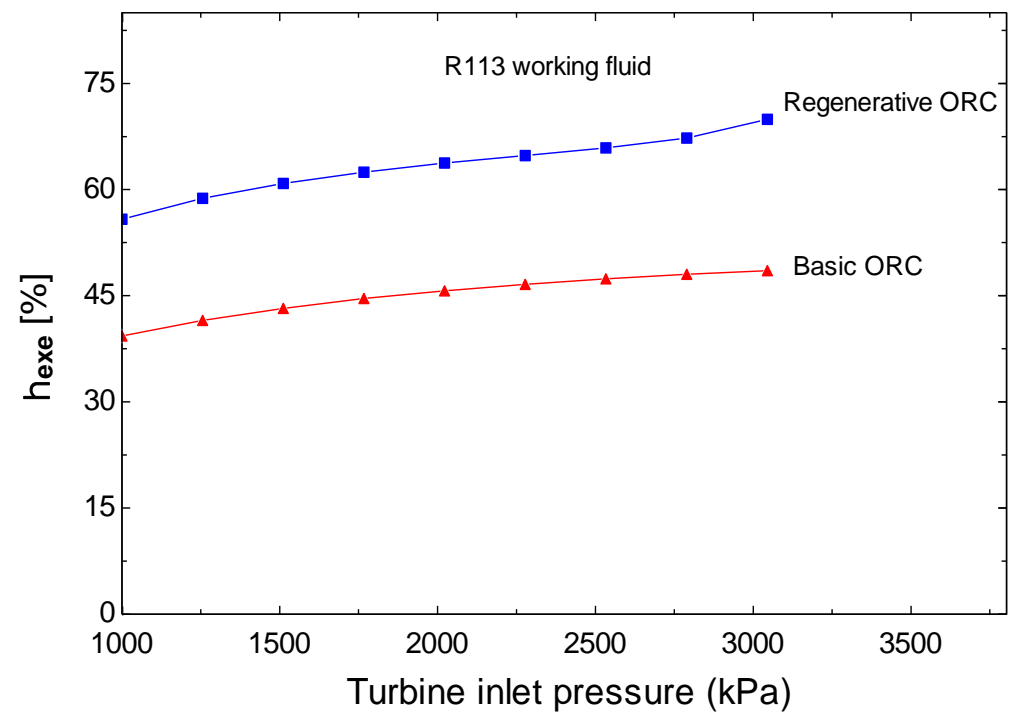

Figure 7. Comparison of exergy efficiency for basic and regenerative ORC

According to results presented in Figure 7, the second law efficiency of regenerative ORC is about $42 \%$ higher than the second law efficiency of basic ORC in low-inlet pressures while with using regenerative ORC in high- pressures, the thermal efficiency increases by approximately $44 \%$ compared with basic ORC.

Figure 8 illustrates the change of the total irreversibility rate for the basic and regenerative ORC using R113 with increased the turbine inlet pressure under the same assumptions. According to analysis, the total irreversibility value decreases and reaches to its minimum value and then it increases afterwards with the increase in the turbine inlet pressure in each configurations. The maximum total irreversibility rates or the exergy destruction 
are calculated as $77,34 \mathrm{~kW}$ and $65,63 \mathrm{~kW}$ in $1 \mathrm{MPa}$ turbine inlet pressure for basic and regenerative ORC. The regenerative ORC generates about $18 \%$ less the total irreversibility rate when compared with basic ORC.

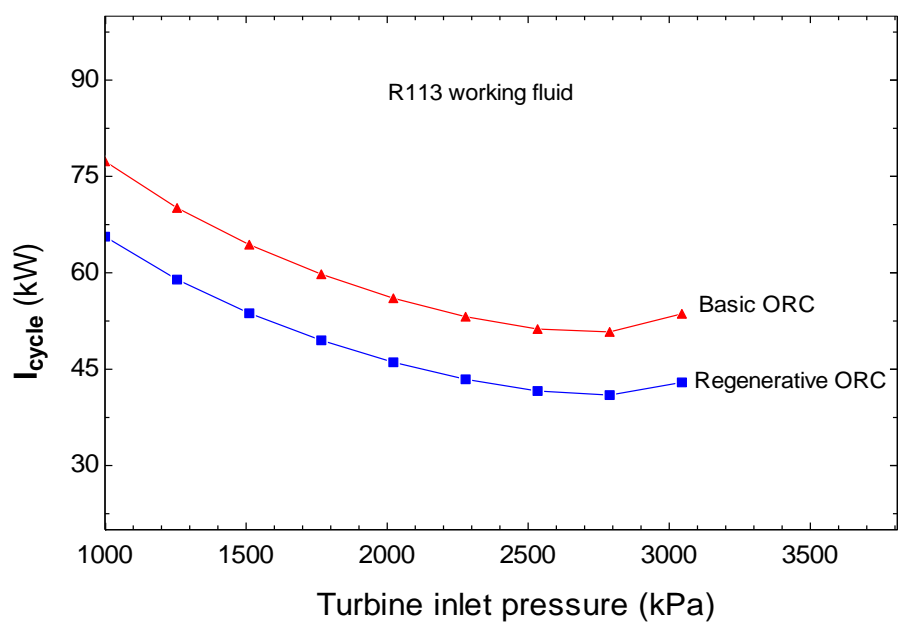

Figure 8. Comparison of total irreversibility value for basic and regenerative ORC

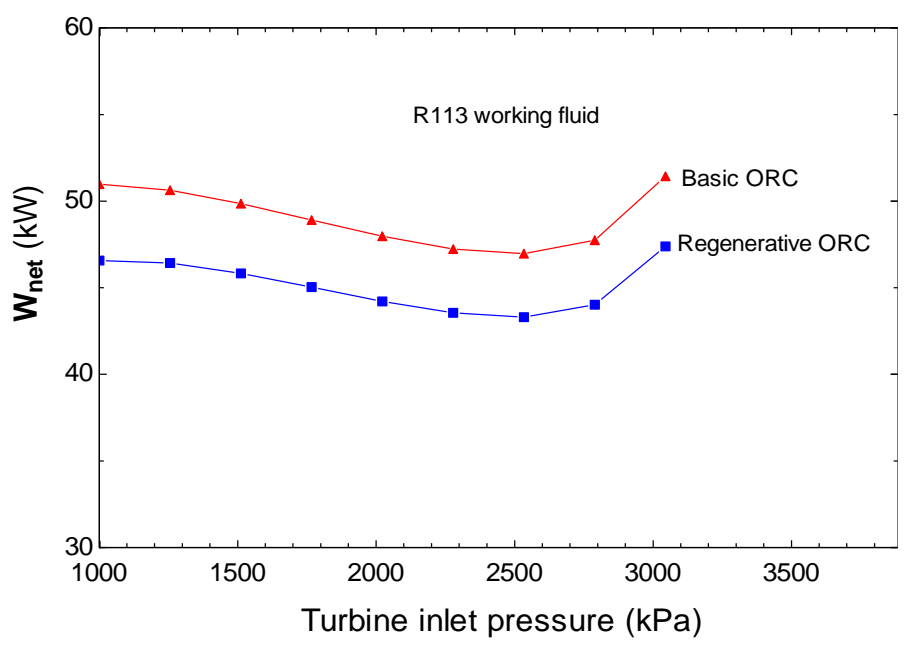

Figure 9. Comparison of the net power for basic and regenerative ORC

When compared the net power of the working fluids, according to Figure 9 for basic and regenerative $\mathrm{ORC}$, the net power decreases before and then increases with the increase of the turbine inlet pressure. The net power of basic ORC is about $4 \%$ higher than the net power of regenerative ORC.

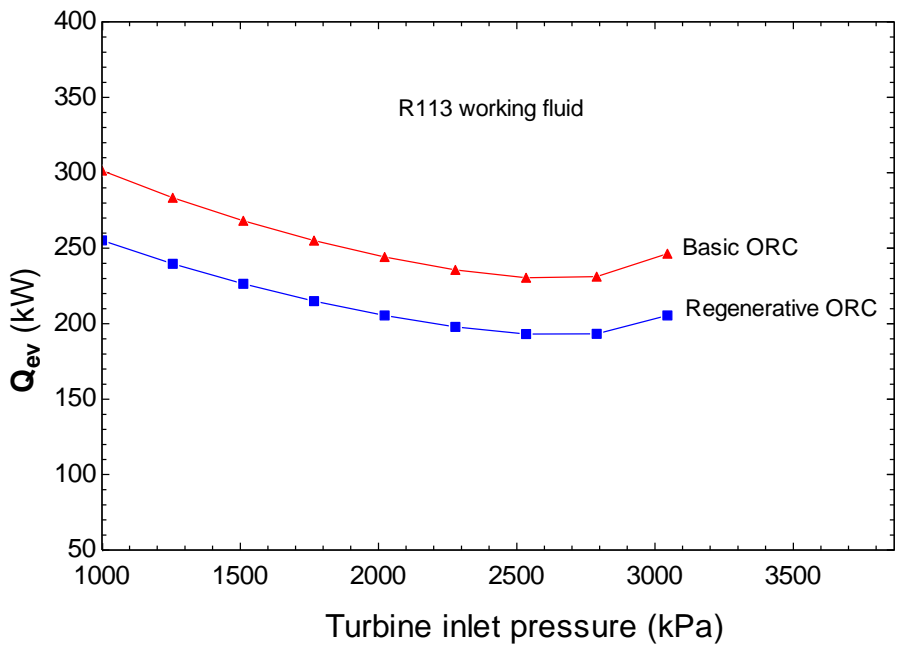

Figure 10. Comparison of heat input for basic and regenerative ORC 
As is seen the Figure 10, the heat input has the same tendency with net power. The maximum heat input is calculated as $301,4 \mathrm{~kW}$ and $255,53 \mathrm{~kW}$ in $1 \mathrm{MPa}$ turbine inlet pressure for basic and regenerative ORC respectively. The regenerative ORC has about $15 \%$ less the heat input compared with basic ORC for R113 working fluid.

\section{CONCLUSION}

The selection of working fluids according to appropriate turbine inlet pressure has a significant influence on the performance of an basic and regenerative ORC. The working fluid of an ORC determines thermal efficiency, safety, stability, environmental impact, and economic profitability of the system. So, In this study, basic and regenerative organic Rankine cycles are analyzed to convert waste heat energy to power. We have selected the five organic working fluids as working fluid namely, R113, R114, R227ea, R245fa and R600a and evaluated basic and regenerative ORC in terms of the first and second law thermodynamics. We have investigated the effects of turbine inlet pressure on different parameters. According to analysis, R113 working fluid has represented the best performance with thermal and exergy efficiency and irreversibility rate. The worst efficiency has been calculated for R227ea which has been followed by R600a, R114 and R245fa. Regenerative ORC has has higher first and second law efficiencies than basic ORC with $23,1 \%$ and $69,9 \%$ respectively. However, the regenerative ORC has producted less irreversibility rate, net power and heat input values than basic ORC. Also, the influence of the boiling point temperature on the efficiency for basic and regenerative ORC has determined in this paper.

\section{NOMENCLATURE}

$\begin{array}{ll}\text { c } & \text { condenser } \\ \text { cycle } & \text { cycle } \\ \mathrm{e} & \text { evaporator } \\ \dot{E} & \text { energy }[\mathrm{kW}] \\ E x & \text { exergy }[\mathrm{kW}] \\ \text { exe } & \text { exergetic } \\ \text { exp } & \text { expander } \\ \mathrm{h} & \text { specific enthalpy }[\mathrm{kj} / \mathrm{kg}] \\ \dot{m} & \text { mass flow rate }[\mathrm{kg} / \mathrm{s}] \\ \mathrm{hf} & \text { hot fluid } \\ \dot{I} & \text { irreversibility }[\mathrm{kW}] \\ \text { net } & \text { net } \\ \mathrm{o} & \text { ambient } \\ \mathrm{ORC} & \text { organic Rankine cycle } \\ \mathrm{p} & \text { pump } \\ \mathrm{pp} & \text { pinch point } \\ \dot{Q} & \text { heat }[\mathrm{kW}] \\ \mathrm{s} & \text { specific entropy }[\mathrm{kj} / \mathrm{kgK}] \\ \mathrm{T} & \text { temperature }[\mathrm{K}] \\ \mathrm{T}_{\mathrm{L}} & \text { the low temperature of cold source }[\mathrm{K}] \\ \Delta T & \text { temperature differential }[\mathrm{K}] \\ \dot{W} & \text { power }[\mathrm{kW}] \\ \eta & \text { efficiency }\end{array}$

\section{REFERENCES}

[1] Liu, B. T., Chien, K. H., Wang, C. -C. (2004). Effect of working fluids on organic Rankine cycle for waste heat recovery. Energy, 29(8), 1207-1217.

[2] Chen, Y., Lundqvist, P., Johansson, A., Platell, P.A. (2006). Comparative study of the carbon dioxide transcritical power cycle compared with an organic Rankine cycle with R123 as working fluid in waste heat recovery. Applied Thermal Engineering, 26, 2142-2147.

[3] Kanoglu, M., Bolatturk, A. (2008). Performance and parametric investigation of a binary geothermal power plant by exergy. Renewable Energy, 33, 2366-2374.

[4] Roy, J.P., Mishra, M.K., Misra, A. (2011). Performance analysis of an organic Rankine cycle with superheating under different heat source temperature conditions. Applied Energy, 88, 2995-3004. 
[5] Gao, H., Liu, C., He, C., Xu, X., Wu, S., Li, Y. (2012). Performance analysis and working fluid selection of a supercritical organic rankine cycle for low grade waste heat recovery. Energies, 5, 3233-3247

[6] Dai, Y., Wang, J., Gao, L. (2009). Parametric optimization and comparative study of organic Rankine cycle (ORC) for low grade waste heat recovery. Energy Conversion Management, 50, 576 -582.

[7] Kerme, E. D., Orfi, J. (2015). Exergy-based thermodynamic analysis of solar driven organic Rankine cycle. Journal of Thermal Engineering, 1(1), 192-202.

[8] Wang, D., Ling, X., Peng, H. (2012). Performance analysis of double organic Rankine cycle for discontinuous low temperature waste heat recovery. Applied Thermal Engineering, 48, 63-71.

[9] Wang, Z.Q., Zhou, N.J., Guo, J., Wang, X.Y. (2012). Fluid selection and parametric optimization of organic Rankine cycle using low temperature waste heat. Energy, 40, 107-115.

[10] Kaska, O. (2014). Energy and exergy analysis of an organic Rankine for power generation from waste heat recovery in steel industry. Energy Conversion and Management, 77, 108-117.

[11] Zhu, Q., Sun, Z., Zhou, J. (2015). Performance analysis of organic Rankine cycles using different working fluids. Thermal Science, 19, 179-191.

[12] Koroglu, T., Sogut, O.S. (2017). Advanced exergy analysis of an organic Rankine cycle waste heat recovery system of a marine power plant. Journal of Thermal Engineering, 3(2), 1136-1148.

[13] Yu, H., Feng, X., Wang, Y. (2016). Working fluid selection for organic Rankine cycle (ORC) considering the characteristics of waste heat sources. Industrial \& Engineering Chemistry Research, 55, 1309-1321.

[14] Radulovic, J. (2015). Utilization of fluids with low global warming potential in supercritical organic Rankine cycle. Journal of Thermal Engineering, 1(1), 24-30.

[15] Akkaya, A.V. (2017). Performance analyzing of an organic Rankine cycle under different ambient conditions. Journal of Thermal Engineering, 3(5), 1498-1504.

[16] Mago, P. J., Chamra, L. M., Srinivasan, K., Somayaji, C. (2008). An examination of regenerative organic Rankine cycles using dry fluids. Applied Thermal Engineering, 28 (8), 998-1007.

[17] Hajabdollahi, H., Ganjehkaviri, A., Jaafar, M.N.M. (2015). Thermo-economic optimization of RSORC (regenerative solar organic Rankine cycle) considering hourly analysis. Energy, 87, 369-380.

[18] Wang, M., Wang, J., Zhao, Y., Dai, Y. (2013). Thermodynamic analysis and optimization of a solar-driven regenerative organic Rankine cycle (ORC) based on flat-plate solar collectors. Applied Thermal Engineering, 50, 816-825.

[19] Darvish, K., Ehyaei, M.A., Atabi, F., Rosen, M.A. (2015). Selection of optimum working fluid for organic Rankine sysles by exergy and exergy-economic analyses. Sustainability, 7, 15362-15383.

[20] Roy, J.P., Misra, A. (2012). Parametric optimization and performance analysis of a regenerative Organic Rankine Cycle using R-123 for waste heat recovery. Energy, 39, 227-235.

[21] Imran, M., Park, B., Kim, H., Lee, D., Usman, M., Heo, M. (2014). Thermo-economic optimization of regenerative organic Rankine cycle for waste heat recovery applications. Energy Conversion and Management, $87,107-118$.

[22] Cengel, Y.A., Boles M.A.(2011). Thermodynamics: An Engineering Approach, 7th ed., New York, USA: McGraw-Hill Inc.

[23] http://www.coolprop.org/fluid_properties/PurePseudoPur ehtml\#thermodynamic-properties-of-fluid, ( accessed: 02.03.2017) 